\title{
REVIEW OF RENAL TUMORS ASSOCIATED WITH \\ BIRT-HogG-DubÉ SYNDROME WITH FOCUS ON CLINICAL AND PATHOBIOLOGICAL ASPECTS
}

\author{
Naoto Kuroda ${ }^{1}$, Mitsuko Furuya ${ }^{2}$, Yoji Nagashima ${ }^{2}$, Hiroko Gotohda ${ }^{3}$, Fumi Kawakami ${ }^{4}$, \\ Suzuko Moritani ${ }^{5}$, Satoshi Ota ${ }^{6}$, Milan Hora $^{7}$, Michal Michal $^{8}$, Ondrej Hes ${ }^{8}$, \\ Yukio Nakatani ${ }^{6}$
}

\author{
${ }^{1}$ Department of Diagnostic Pathology, Kochi Red Cross Hospital, Kochi, Japan \\ ${ }^{2}$ Department of Molecular Pathology, Yokohama City University Graduate School of Medicine, Yokohama, Japan \\ ${ }^{3}$ Division of Pathology, JA Hokkaido Koseiren Sapporo Kousei Hospital, Sapporo, Japan \\ ${ }^{4}$ Department of Diagnostic Pathology, Kobe University Hospital, Kobe, Japan \\ ${ }^{5}$ Department of Advanced Diagnosis, Division of Pathology, Nagoya Medical Center, Nagoya, Japan \\ ${ }^{6}$ Department of Diagnostic Pathology, Chiba University Graduate School of Medicine, Chiba, Japan \\ ${ }^{7}$ Department of Urology, Charles University Hospital Plzen, Czech Republic \\ ${ }^{8}$ Department of Pathology, Charles University in Prague, Faculty of Medicine in Plzen, Czech Republic
}

\begin{abstract}
Birt-Hogg-Dubé syndrome (BHDS) is an autosomal dominant inherited disorder characterized by clinical features of skin lesions, pulmonary lesions and renal tumor. The gene responsible for this syndrome is located on chromosome $17 \mathrm{p} 11.2$ and designated as FLCN. In this article, we review renal tumors associated with BHDS with a focus on clinical and pathobiological aspects. Renal tumors often occur multifocally or bilaterally in the imaging analyses or gross examination. Histological examination of renal tumors includes a variety of subtypes such as hybrid oncocytic tumor, chromophobe renal cell carcinoma (RCC), oncocytoma, clear cell RCC and papillary RCC. The histologic discordance in multiple tumors seems to be characteristic of this syndrome. Oncocytosis is observed histologically in about half of the cases. Several investigations have elucidated that folliculin may be involved in the mammalian target of rapamycin (mTOR) pathway recently. Renal tumors composed of clear cells may behave in an aggressive fashion. However, renal tumors including hybrid oncocytic tumor, chromophobe RCC and oncocytoma behave mostly in an indolent fashion.
\end{abstract}

Key words: review, renal tumor, Birt-Hogg-Dubé syndrome.

\section{Introduction and history}

Birt, Hogg and Dubé reported several members of kin with thyroid cancer and fibrofolliculoma occurring in an inherited autosomal dominant fashion [1]. This syndrome was later designated as Birt-HoggDubé syndrome (BHDS). However, two years earlier, Hornstein and Knickenberg described a distinct entity in two siblings with multiple perifollicular fi- bromas, multiple acrochordons and intestinal polyps [2]. Their father had bilateral renal cysts and bilateral lung cysts. The authors suggested that this disorder is probably based on a genetic trait. The disease has been named as Hornstein-Knickenberg syndrome. Nowadays, some investigators consider that these two syndromes are the same entity [3-6]. Accordingly, Happle proposes that this syndrome should be renamed as Hornstein-Birt-Hogg-Dubé syndrome [6]. 
The association of renal tumors in BHDS was first described in 1993 [7]. In this article, we present an overview of renal tumors associated with BHDS with a focus on clinical and pathobiological aspects.

\section{Definition of the entity}

BHDS is an autosomal dominant disorder characterized by the association of lesions affecting three different systems: skin lesions such as fibrofolliculoma, trichodiscoma and acrochordon; pulmonary lesions including cysts and spontaneous pneumothorax; and renal tumors [1, 2, 8-11]. The diagnostic criteria are as follows: Major criteria, 1) At least five fibrofolliculomas or trichodiscomas, at least one of them confirmed histologically, occurring in adult onset, 2) Pathogenic FLCN germline mutation; Minor criteria, 1) Multiple lung cysts, bilateral basally located lung cysts with no other apparent cause, with or without spontaneous primary pneumothorax, 2) Renal cancer, early onset ( $<50$ years) or multifocal or bilateral renal cancer, or renal tumor composed of mixed chromophobe and oncocytic morphology, 3) A first-degree relative with BHDS. When patients fulfill one major or two minor criteria, the diagnosis of BHDS is feasible [12].

\section{Epidemiology}

BHDS occurs in approximately $1 / 200,000$ people $[13,14]$. Renal tumors associated with BHDS are diagnosed at the age ranging from 20 to 75 years, but often occur before 50 years of age $[3,5$, 15-17]. Renal tumors occur in $25-35 \%$ of patients with BHDS [14, 18]. There is a male predominance in renal tumors associated with BHDS [18]. The estimated penetrance of renal cancer in FLCN gene mutation carriers in BHDS families is $16 \%$ at 70 years of age [17]. The risk of developing renal tumors in BHDS-affected patients is approximately 7 times higher than in non-BHDS-affected patients [19]. Skin lesions arising in face, neck and anterior trunk regions are observed in approximately $80 \%$ of patients with BHDS [14]. Pulmonary cyst and spontaneous pneumothorax are identified in over $80 \%$ and nearly $25 \%$ of BHDS-affected patients [14]. The risk of developing spontaneous pneumothorax in BHDS-affected patients is approximately 50 times higher than in non-BHDS-affected patients [19].

\section{Other clinical features}

The association of parotid gland oncocytoma, thyroid carcinoma, prostatic carcinoma, breast fibroadenomatosis, breast sarcoma, jaw cancer, and colon carcinoma has been repeatedly described [16, 19-21]. Regarding skin/soft tissue lesions, focal cutaneous mucinosis, trichoblastomas, basal cell carcinomas, angiolipomas, lipomas, collagenomas, connective tissue nevi, malignant melanomas, oral papules and perivascular fibromas may be observed in BHDS $[20$, 22-24]. Aplasia of the internal carotid artery and flecked chorioretinopathy were also reported [20]. However, whether these diseases are really related to BHDS remains unknown.

\section{Imaging findings}

Ultrasound sonography or computed tomography scan of the kidney usually shows unilateral and bilateral solid lesions [3, 25-27]. Preoperative imaging disclosed 5.3 tumors per BHDS patients on average $[18,28]$. The lesions are usually multifocal [25]. Renal cysts may be seen [29].

\section{Pathological findings}

\section{Macroscopic findings}

The tumors usually form a well-demarcated, unencapsulated mass and the cut surface shows homogeneous tan to brown color $[30,31]$. Necrosis is not frequent. However, a central scar may be seen [32].

\section{Microscopic findings}

A variety of histological subtypes including hybrid oncocytic tumor, chromophobe RCC, oncocytoma, papillary RCC and clear cell RCC have been observed [9, 17, 19, 20, 22, 30, 33-35]. Hybrid oncocytic tumors have both areas reminiscent of chromophobe RCC having a well-defined cell border, pyknotic nuclei and perinuclear halo and oncocytoma showing ill-defined cell borders, finely granular eosinophilic cytoplasm and round nuclei [18] (Fig. 1A). In some hybrid oncocytic tumors, clear cells may be focally seen $[8,30]$ (Fig. 1B). Papillary RCC with oncocytic change, clear cell RCC with focal papillary structures, RCC with a mixture of eosinophilic and focal clear cells with tubulopapillary architecture, sarcomatoid RCC and unclassified RCC have been described $[17$, $29,31,36,37]$. The association with renal angiomyolipoma has also been reported [38, 39]. Discordance of histological subtypes is observed in $80 \%$ of bilateral/multiple renal tumors associated with BHDS [5, 40]. Renal cysts are also usually seen [41, 42]. Multifocal renal oncocytosis is observed in the surrounding grossly normal renal parenchyma in 50 to $58 \%$ of patients [43, 44] (Fig. 1C). Renal oncocytosis is characterized by a spectrum of oncocytic changes that diffusely involve the kidney parenchyma and may include a dominant oncocytic neoplasm, smaller oncocytic nodules, infiltrative appearing oncocytic cells, cortical cysts lined with oncocytic cells, and oncocytic change in non-neoplastic tubules [45]. Recently, we 
found a characteristic feature of renal tumors associated with BHDS, i.e. small papillary tufts that are frequently observed in the peripheral area of the tumors (Fig. 1D).

\section{Cytological findings}

Fine needle aspiration cytology showed sheets of oncocytic cells with scattered, slightly larger, clear cells [46].

\section{Molecular genetic findings}

The FLCN gene is mapped to chromosome $17 \mathrm{p} 11.2$ and it is suggested that this gene acts as a tumor suppressor gene because FLCN gene mRNA is expressed in the normal kidney and it is not found in renal tumors of BHDS patients $[14,34,36,47-$ 50]. The germline FLCN gene mutation detection rate in BHDS patients is estimated to reach 84 to $88 \%$ of patients $[21,51]$. The FLCN gene consists of 14 exons and most of the mutations have been reported in exon 4-14 [21, 51, 52] (Fig. 2). The hotspot of FLCN gene mutation is considered to be located in exon $11[21,51]$. The mutation patterns of the FLCN gene consist of a splice site in introns, deletions, insertions, nonsense, deletion/insertion and missense $[21,51]$. Insertions or deletions in this region were found in more than $40 \%$ of BHDS families $[27,48]$. Intragenic deletions and duplication in the FLCN gene have also been identified in BHDS lacking the FLCN gene mutation [53]. Two hits represented by germline mutation in one allele and followed by somatic mutation $(53 \%)$ in the other allele or loss of heterozygosity $(17 \%)$ at the FLCN gene locus in the other allele cause BHDS-related renal tumors [34]. BHDS-related renal tumors are genetically distinct from other renal tumors including chromophobe RCC and oncocytoma. Additionally, increased expression of mitochondria- and oxidative phosphorylation-associated genes has been described in BHDS-derived renal tumors [54]. The mechanism leading to damage of the FLCN gene that leads to renal tumors remains unknown [55]. The wide spec-
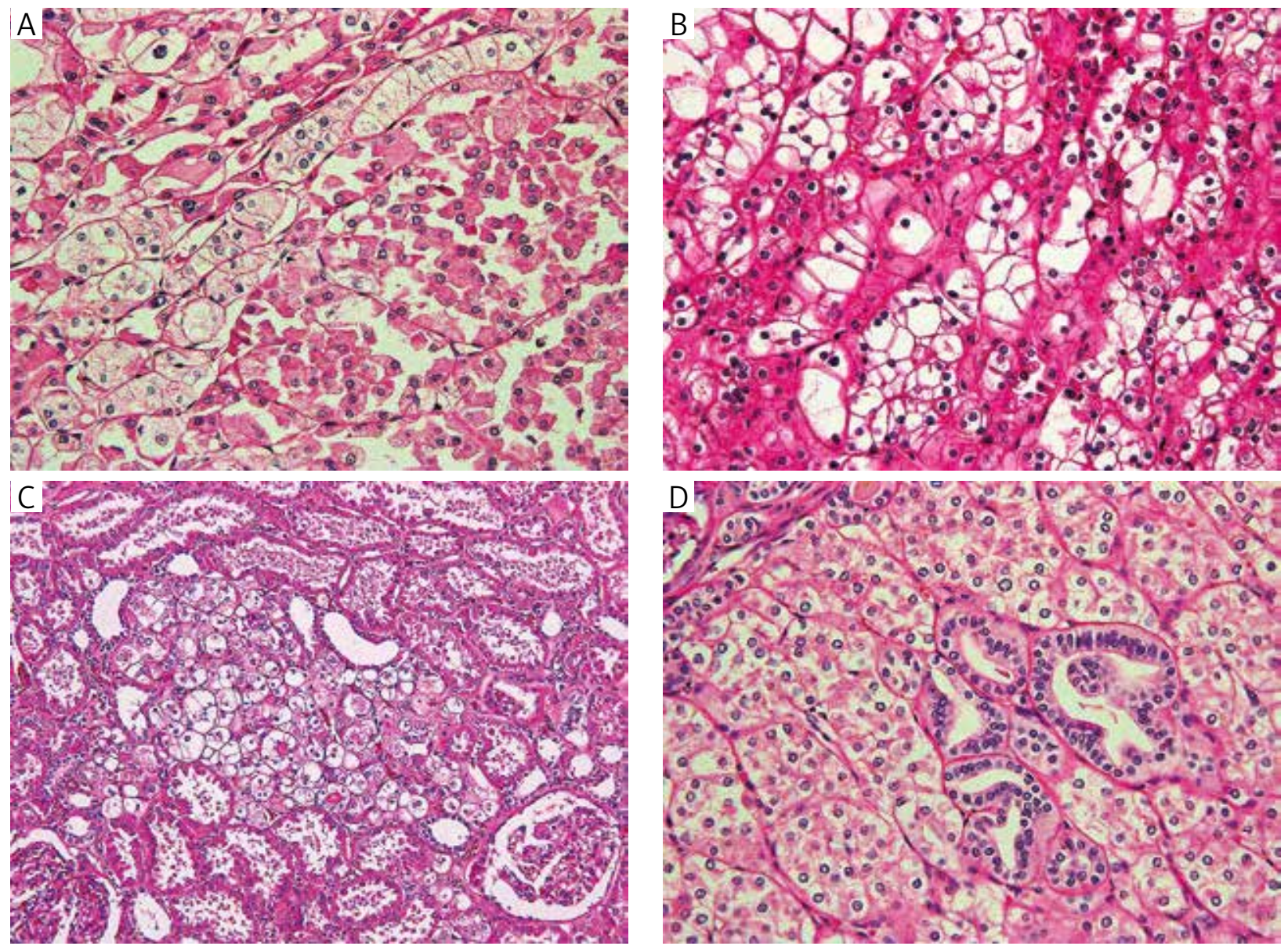

Fig. 1. Microscopic findings of BHDS-associated renal tumor. A) Hybrid oncocytic tumor has discrete areas of chromophobe RCC (left) and oncocytoma (right). B) In hybrid oncocytic tumor, clear cell change of neoplastic cells is noted. C) Renal oncocytic change with focal clear cell change is seen in the grossly normal-looking renal parenchyma. D) Small papillary tufts are often observed in the peripheral area of the tumor 

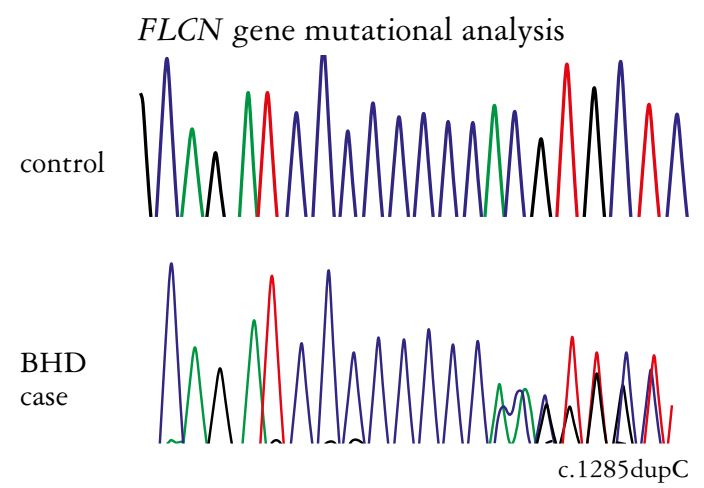

Fig. 2. Direct sequencing mutational analysis of FLCN gene in peripheral blood leucocytes of a BHDS patient. The FLCN gene mutation (cytosine duplication) is observed in exon 11

trum of renal histological types suggests that the $F L C N$ gene may play a vital role in the differentiation process of renal tubular cells [20]. Namely, FLCN gene mutation affects the progenitor cells of proximal and distal tubules and collecting ducts, and gene mutation alters the composition of the extracellular matrix, producing structural or microenvironmental abnormalities that affect these tubular cells, and lead to uncontrolled cellular proliferation [48]. The FLCN gene is thought to be involved in energy and/ or nutrient sensing through AMPK and mammalian target of rapamycin (mTOR) signaling [56].

\section{Phenotype-genotype correlation}

So far, no apparent genotype-phenotype correlations have been recognized [21,31]. However, Schmidt et al. suggest that germline deletion of cytosine at exon 11 in the FLCN gene may be related to the occurrence of fewer renal tumors in BHDS patients than those associated with insertion of cytosine at the same hotspot mutation [51].

\section{FLCN gene abnormalities leading to syndromes other than BHDS}

The germline FLCN gene mutation was detected in $4.3 \%$ of patients with apparent nonsyndromic clear cell RCC susceptibility [57]. Somatic FLCN gene inactivation may occur in a subset of clear cell RCCs and colorectal cancer [58]. Loss of heterozygosity at the FLCN gene locus and promoter methylation of the FLCN gene were identified in $36 \%$ and $28 \%$ of various subtypes of sporadic renal tumors, respectively. These results suggest that the FLCN gene may play a major role in renal cancer tumorigenesis [59]. However, it should be noted that FLCN gene mutations are only rarely found in sporadic chromophobe RCC or renal oncocytoma [60].

\section{Differential diagnosis}

Renal oncocytosis associated with renal failure/ hemodialysis or renal sporadic oncocytosis should be strictly distinguished from BHDS by checking the detailed clinical information including family history and associated disease [61]. In renal oncocytosis of sporadic type, no mutation of the FLCN gene has been identified so far [62]. When the renal tumor is solitary, and family history or associated diseases are absent, sporadic hybrid oncocytic/chromophobe tumor should be listed in the differential diagnosis $[32,63]$. A number of previously described occurrences of familial oncocytoma have been found to have BHDS [41].

\section{Clinical management and therapy}

The clinical surveillance of BHDS patients should be initiated at the age of 20 years with focus on renal tumor occurrence [12]. CT scan is more sensitive than ultrasound sonography, but repeated CT scanning would cause an unacceptably high cumulative radiation dose [12]. Accordingly, annual renal MRI is recommended as the acceptable surveillance modality [12]. The same as renal tumors of other familial syndrome are managed [14], mere close observation should be undertaken until the largest tumor size reaches $3 \mathrm{~cm}$. When the largest tumor exceeds 3 to $4 \mathrm{~cm}$ in the largest diameter, nephron-sparing surgery should be considered [12, 14, 25, 64-66]. If partial nephrectomy is not technically suitable, onetime radical nephrectomy should be performed. For lesions smaller than $3 \mathrm{~cm}$, cryoablation or radiofrequency ablation might be preferred [12]. Ablative therapies including cryoablation or radiofrequency ablation may be suitable for patients with multiple small renal tumors such as familial syndrome [67]. As the FLCN gene is thought to be involved in energy sensing through the AMPK and mTOR pathways, mTOR inhibitors might be effective in patients with local recurrence or distant metastases $[12,42$, $43,56,65,68$ ]. Patients with BHDS-associated renal tumors should be more aggressively managed than those with non-BHDS-associated renal tumors because of their histological discordance [69]. Early molecular diagnosis in families of BHDS facilitates the management and prevention of RCC [42].

\section{Prognosis}

Renal tumors associated with BHDS usually pursue a favorable clinical course, probably because the clinical behavior of hybrid oncocytic tumor, chromophobe RCC, and oncocytoma is usually not aggressive. Tumors are also mostly disclosed at a low clinical stage $[5,18,40]$. The clinical behavior of hybrid oncocytic tumor is still entirely uncertain and should 
be proved by studies with available long follow-up. It may be reasonable to assume that renal oncocytic tumors exhibit biological behavior between oncocytoma and low-grade chromophobe RCC [8]. However, some cases have had metastases or a dismal outcome. The presence of clear cell components in renal tumors may reflect the worse prognosis $[5,15,25,70]$.

\section{Future perspectives}

We recently reported a case of multiple chromophobe RCCs with renal angiomyolipoma. However, we could not identify the FLCN gene mutation in this case $[71]$. On the one hand, a close relationship between BHDS and tuberous sclerosis complex in the common pathway through $\mathrm{mTOR}$ and clinical overlapping has been reported [38, 39, 72]. On the other hand, multiple chromophobe RCCs have been described in germline PTEN mutation Cowden syndrome [73]. In order to elucidate the relationship among BHDS, tuberous sclerosis complex and Cowden syndrome, a further examination in a large cohort study will be required.

Folliculin negatively regulates the AMPK/mTOR pathway, via complex formation with folliculin interacting proteins 1 and 2 (FNIP1 and FNIP2) to bind the g-subunits of AMPK [56, 74, 76-78]. Thus, enhancement of mTORC1 and mTORC2 functions may provide a novel therapeutic strategy for patients with BHDS. Additionally, mTOR inhibitors including rapamycin will also be potential therapeutic agents in the near future [76, 79].

The authors declare no conflict of interest. This study was in part supported by a Grant-in-Aid from the Japanese Ministry of Welfare and Labor (to M. Furuya and Y. Nakatani).

\section{References}

1. Birt AR, Hogg GR, Dubé WJ. Hereditary multiple fibrofolliculoma with trichodiscomas and acrochordons. Arch Dermatol 1977; 13: 1676-1677.

2. Hornstein OP, Knickenberg M. Perifollicular fibromatosis cutis with polyp of the colon-A cutaneo-intestinal syndrome sui generis. Arch Dermatol Res 1975; 253: 161-175.

3. Choyke PL, Glenn GM, Walther MM, et al. Hereditary renal cancers. Radiology 2003; 226: 33-46.

4. Burgdorf WH. Cancer-associated genodermatoses: A personal history. Exp Dermatol 2006; 15: 653-666.

5. Coleman JA. Familial and hereditary renal cancer syndrome. Urol Clin N Am 2008; 35: 563-572.

6. Happle R. Hornstein-Birt-Hogg-Dubé syndrome: A renaming and reconsideration. Am J Med Genet 2012; 158A: $1247-$ 1251.

7. Roth JS, Rabinowitz AD, Benson M, et al. Bilateral renal cell carcinoma in the Birt-Hogg-Dubé syndrome. J Am Acad Dermatol 1993; 29: 1055-1056.
8. Adley BP, Smith ND, Nayar R, et al. Birt-Hogg-Dubé syndrome. Clinicopathologic findings and genetic alterations. Arch Pathol Lab Med 2006; 130: 1865-1870.

9. Hansel DE. Genetic alterations and histopathologic findings in familial renal cell carcinoma. Histol Histopathol 2006; 21: 437-444.

10. Furuya M, Tanaka R, Koga S, et al. Pulmonary cyst of BirtHogg-Dubé syndrome: A clinicopathologic and immunohistochemical study of 9 families. Am J Surg Pathol 2012; 36: 589-600.

11. Furuya M, Nakatani Y. Birt-Hogg-Dubé syndrome: clinicopathological features of the lung. J Clin Pathol 2013; 66: 178-186.

12. Menko FH, van Steensel MA, Giraud S, et al. Birt-Hogg-Dubé syndrome: diagnosis and management. Lancet Oncol 2009; 10: 1199-1206.

13. Ferzli PG, Millet CR, Newman ND, et al. The dermatologist's guide to hereditary syndromes with renal tumors. Cutis 2008; 81: 41-48.

14. Pfaffenroth EC, Linehan WM. Genetic basis for kidney cancer: Opportunity for disease-specific approaches to therapy. Expert Opin Biol Ther 2008; 8: 779-790.

15. Kluijt I, de Jong D, Teetstra HJ, et al. Early onset of renal cancer in a family with Birt-Hogg-Dubé syndrome. Clin Genet 2009; 75: 537-543

16. Palmirotta R, Savonarola A, Ludovici G, et al. Association between Birt Hogg Dubé syndrome and cancer predisposition. Anticancer Res 2010; 30: 751-758.

17. Houweling AC, Gijezen LM, Jonker MA, et al. Renal cancer and pneumothorax risk in Birt-Hogg-Dubé syndrome: an analysis of 115 FLCN mutation carriers from 35 BHD families. Br J Cancer 2011; 105: 1912-1919.

18. Pavlovich CP, Walther MM, Eyler RA, et al. Renal tumors in the Birt-Hogg-Dubé syndrome. Am J Surg Pathol 2002; 26: $1542-1552$

19. Zbar B, Alvord G, Glenn G, et al. Risk of renal and colonic neoplasms and spontaneous pneumothorax in the Birt-HoggDubé syndrome. Cancer Epidemiol Biomarkers Prev 2002; 11: 393-400.

20. Welsch MJ, Krunic A, Medenica MM. Birt-Hogg-Dubé syndrome. Int J Dermatol 2005; 44: 668-673.

21. Toro JR, Wei MH, Glenn GM, et al. BHD mutations, clinical and molecular genetic investigations of Birt-Hogg-Dubé syndrome: a new series of 50 families and a review of published reports. J Med Genet 2008; 45: 321-331.

22. Lindor NM, Hand J, Burch PA, et al. Birt-Hogg-Dubé syndrome: an autosomal dominant disorder with predisposition to cancers of the kidney, fibrofolliculoma, and focal cutaneous mucinosis. Int J Dermatol 2001; 40: 653-656.

23. Imada K, Dainichi T, Yokomizo A, et al. Birt-Hogg-Dubé syndrome with clear-cell and oncocytic renal tumour and trichoblastoma associated with a novel FLCN mutation. Br J Dermatol 2009; 160: 1335-1362.

24. Mota-Burgos A, Acosta EH, Marquez FV, et al. Birt-HoggDubé syndrome in a patient with melanoma and novel mutation in the FLCN gene. Int J Dermatol 2013; 52: 323-326.

25. Pavlovich CP, Grubb RL, Hurley K, et al. Evaluation and management of renal tumors in the Birt-Hogg-Dubé syndrome. J Urol 2005; 173: 1482-1486.

26. Fahmy W, Safwat AS, Bissada NK, et al. Miltiple/bilateral renal tumors in patients with Birt-Hogg-Dubé syndrome. Int Urol Nephrol 2007; 39: 995-999.

27. Warwick G, Izatt L, Sawicka E. Renal cancer associated with recurrence spontaneous pneumothorax in Birt-Hogg-Dubé syndrome: a case report and review of the literature. J Med Case Rep 2010; 4: 106

28. Sudarshan S, Linehan WM. Genetic basis of cancer of the kidney. Sem Oncol 2006; 33: 544-551. 
29. Toro JR, Glenn G, Duray P, et al. Birt-Hogg-Dubé syndrome. A novel marker of kidney neoplasia. Arch Dermatol 1999; 135: 1195-1202.

30. Abbosh PH, Grubb RL, Cao D, et al. Hybrid renal tumors in Birt-Hogg-Dubé syndrome. J Urol 2011; 186: 2413-2414.

31. Nagashima Y, Furuya M, Gotohda H, et al. FLCN gene-mutated renal cell neoplasms: mother and daughter cases with a novel germline mutation. Int J Urol 2012; 19: 468-470.

32. Hes O, Petersson F, Kuroda N, et al. Renal hybrid oncocytic/ chromophobe tumors. A review. Histol Histopathol 2013; 28: 1257-1264.

33. Schmidt LS. Birt-Hogg-Dubé syndrome, a genodermatosis that increases risk for renal carcinoma. Curr Mol Med 2004 4: 877-885.

34. Vocke CD, Yang Y, Pavlovich CP, et al. High frequency of somatic frameshift BHD gene mutations in Birt-Hogg-Dubé-associated renal tumors. J Natl Cancer Inst 2005; 97: 931-935.

35. Linehan WM. Genetic basis of kidney cancer: role of genomics for the development of disease-based therapeutics. Genome Res 2012; 22: 2089-2100.

36. Khoo SK, Bradley M, Wong FK, et al. Birt-Hogg-Dubé syndrome: mapping of a novel hereditary neoplasia gene to chromosome 17p12-q11.2. Oncogene 2001; 20: 5239-5242.

37. Murakami T, Sano F, Huang Y, et al. Identification and characterization of Birt-Hogg-Dubé associated renal carcinoma. J Pathol 2007; 211: 524-531.

38. Byrne M, Mallipeddi R, Pichert G, Whittaker S. Birt-HoggDubé syndrome with a renal angiomyolipoma: further evidence of a relationship between Birt-Hogg-Dubé syndrome and tuberous sclerosis complex. Australas J Dermatol 2012; 53: 151-154.

39. Tobino K, Seyama K. Birt-Hogg-Dubé syndrome with renal angiomyolipoma. Intern Med 2012; 51: 1279-1280.

40. Coleman JA, Russo R. Hereditary and familial kidney cancer. Curr Opin Urol 2009; 19: 478-485.

41. Takahashi M, Kahnoski R, Gross D, et al. Familial adult renal neoplasia. J Med Genet 2002; 39: 1-5.

42. Morrison PJ, Donnelly DE, Atkinson AB, Maxwell AP. Advances in the genetics of familial renal cancer. Oncologist 2010; 15: 532-538.

43. Linehan WM, Pinto PA, Bratslavsky G, et al. Hereditary kidney cancer: unique opportunity for disease-based therapy. Cancer 2009; 115: 2252-2261.

44. Rosner I, Bratslavsky G, Pinto PA, et al. The clinical implication of the genetics of renal cell carcinoma. Urol Oncol 2009; 27: 131-136.

45. Przybycin CG, Magi-Galluzzi C, McKenney JK. Hereditary syndromes with associated with renal neoplasia: A practical guide to histologic recognition in renal tumor resection specimens. Adv Anat Pathol 2013; 20: 245-263.

46. Adley BP, Schafernak KT, Yerdandi AV, et al. Cytologic and histologic findings in multiple renal hybrid oncocytic tumors in a patient with Birt-Hogg-Dubé syndrome. Acta Cytol 2006; 50: $1-6$.

47. Schmidt LS, Warren MB, Nickerson ML, et al. Birt-HoggDubé syndrome, a genodermatosis associated with spontaneous pneumothorax and kidney neoplasia, maps to chromosome 17p11.2. Am J Hum Genet 2001; 69: 876-882.

48. Nickerson ML, Warren MB, Toro JR, et al. Mutations in a novel gene lead to kidney tumors, lung wall defects, and benign tumors of the hair follicle in patients with the Birt-Hogg-Dubé syndrome. Cancer Cell 2002; 2: 157-164.

49. Warren MB, Torres-Cabala CA, Turner ML, et al. Expression of Birt-Hogg-Dubé gene mRNA in normal and neoplastic human tissues. Mod Pathol 2004; 17: 998-1011.

50. Cohen D, Zhou M. Molecular genetics of familial renal cell carcinoma syndromes. Clin Lab Med 2005; 25: 259-277.

51. Schmidt LS, Nickerson ML, Warren MB, et al. Germline BHD-mutation spectrum and phenotype analysis of a large co- hort of families with Birt-Hogg-Dubé syndrome. Am J Hum Genet 2005; 76: 1023-1033.

52. Lim DHK, Rehal PK, Nahorski MS, et al. A new locus-specific database (LSDB) for mutations in the Folliculin (FLCN) gene. Hum Mut 2010; 31: E1043-E1051.

53. Benhammou JN, Vocke CD, Santani A, et al. Identification of intragenic deletions and duplication in the FLCN gene in BirtHogg-Dubé syndrome. Genes Chromosomes Cancer 2011; 50: 466-477.

54. Klomp JA, Petillo D, Niemi NM, et al. Birt-Hogg-Dubé renal tumors are genetically distinct from other renal neoplasias and are associated with up-regulation of mitochondrial gene expression. BMC Medical Genomics 2010; 3: 59.

55. Linehan WM, Vasselli J, Srinivasan R, et al. Genetic basis of cancer of the kidney: disease-specific approaches to therapy. Clin Cancer Res 2004; 10: 6282s-6289s.

56. Baba M, Hong SB, Sharma N, et al. Folliculin encoded by the BHD gene interacts with a binding protein, FNIP1, and AMPK, and is involved in AMPK and mTOR signaling. Proc Natl Acad Sci U S A 2006; 103: 15552-15557.

57. Woodward ER, Ricketts C, Killick P, et al. Familial non-VHL clear cell (conventional) renal cell carcinoma: Clinical features, segregation analysis, and mutation analysis of FLCN. Clin Cancer Res 2008; 14: 5925-5930.

58. da Silva NF, Gentle D, Hesson LB, et al. Analysis of the BirtHogg-Dubé (BHD) tumor suppressor gene in sporadic renal cell carcinoma and colorectal cancer. J Med Genet 2003; 40: 820-824.

59. Khoo SK, Kahnoski K, Sugimura J, et al. Inactivation of BHD in sporadic renal tumors. Cancer Res 2003; 63: 4583-4587.

60. Nagy A, Zoubakov D, Stupar Z, et al. Lack of mutation of the folliculin gene in sporadic chromophobe renal cell carcinoma and renal oncocytoma. Int J Cancer 2004; 109: 472-475.

61. Kuroda N, Tanaka A, Ohe C, et al. Review of renal oncocytosis (multiple oncocytic lesions) with focus on clinical and pathobiological aspects. Histol Histopathol 2012; 27: 1407-1412.

62. Nagashima Y, Mitsuya T, Shioi K, et al. Renal oncocytosis. Pathol Int 2005; 55: 210-215.

63. Petersson F, Gatalica Z, Grossmann P, et al. Sporadic hybrid oncocytic/chromophobe tumor of the kidney: a clinicopathologic, histomorphologic, immunohistochemical, ultrastructural, and molecular cytogenetic study of 14 cases. Virchows Arch 2010; 456: 355-365

64. Gupta GN, Peterson J, Daryanani KA, et al. Oncologic outcomes of partial nephrectomy for multifocal renal cell carcinoma with tumors greater than 4cm. J Urol 2010; 184: 59-63.

65. García-Donas J, Hernando S, Romero N, et al. Knowledge of hereditary renal cancer syndromes: a pending issue for oncologists. Anti-Cancer Drugs 2011; 22: S15-S20.

66. Tefekli A, Akkaya AD, Peker K, et al. Staged, open, no-ischemia nephron-sparing surgery for bilateral-multiple kidney tumors in a patient with Birt-Hogg-Dubé syndrome. Case Rep Med 2012; 2012: 639629.

67. Adamowicz J, Tworkiewicz J, Siekiera J, et al. Ablative therapies for small renal tumors. Contemp Oncol (Pozn) 2013; 17: 24-28.

68. Linehan WM, Bratslavsky G, Pinto PA, et al. Molecular diagnosis and therapy of kidney cancer. Annu Rev Med 2010; 61: 329-343.

69. Boris R, Benhammou J, Merino M, et al. The impact of germline BHD mutation on histologic concordance and clinical management of patients with bilateral renal masses and known unilateral oncocytoma. J Urol 2011; 185: 2050-2055.

70. Leter EM, Koopmans AK, Gille JJ, et al. Birt-Hogg-Dubé syndrome: Clinical and genetic studies of 20 families. J Invest Dermatol 2008; 128: 45-49.

71. Sugimoto K, Takasawa A, Ichimiya S, et al. Multifocal and microscopic chromophobe renal cell carcinomatous lesions as- 
sociated with "capsulomas" without FLCN gene abnormality. Pathol Int 2013; 63: 510-515.

72. Spring P, Fellmann F, Giraud S, et al. Syndrome of Birt-HoggDubé, a histopathological pitfall with similarities to tuberous sclerosis: a report of three cases. Am J Dermatopathol 2013; 35: 241-245.

73. Shuch B, Ricketts CJ, Vocke CD, et al. Germline PTEN mutation Cowden syndrome: an underappreciate form of hereditary kidney cancer. J Urol 2013; 190: 1990-1998.

74. Okoń K. Pathology of renal tumors in adults. Molecular biology, histopathological diagnosis and prognosis. Pol J Pathol 2008; 59: 129-176.

75. Linehan WM, Srinivasan R, Schmidt LS. The genetic basis of kidney cancer: a metabolic disease. Nat Rev Urol 2010; 7: 277-285.

76. Baba M, Furihata M, Hong SB, et al. Kidney-targeted BirtHogg-Dubé gene inactivation in a mouse model: Erk1/2 and Akt-mTOR activation, cell hyperproliferation, and polycystic kidneys. J Natl Cancer Inst 2008; 100: 140-154.

77. Hasumi H, Baba M, Hong SB, et al. Identification and characterization of a novel folliculin-interacting protein FNIP2. Gene 2008; 415: 60-67.

78. Takagi Y, Kobayashi T, Shiono M, et al. Interaction of folliculin (Birt-Hogg- Dubé gene product) with a novel Fnip1-like (FnipL/Fnip2) protein. Oncogene 2008; 27: 5339-5347.

79. Hasumi Y, Baba M, Ajima R, et al. Homozygous loss of BHD causes early embryonic lethality and kidney tumor development with activation of mTORC1 and mTORC2. PNAS 2009; 106: 18722-18727.

\section{Address for correspondence}

Naoto Kuroda MD

Department of Diagnostic Pathology

Kochi Red Cross Hospital

Shin-honmachi 2-13-51, Kochi City

Kochi 780-8562, Japan

tel. $+81-88-822-1201$

fax +81-88-822-1056

e-mail: kurochankochi@yahoo.co.jp 